\title{
Mag. Darka Podmenik KAKO DO DODATNIH ZNANJ, KO DIPLOME NE ZAGOTAVLJAJO (VEČ) USTREZNE ZAPOSLITVE?
}

»Rentabilnost« vlaganja v socialni kapital visoko izobraženih iskalcev zaposlitve

\section{POVZETEK}

$V$ zadnjih desetletjih se je izobraženost prebivalcev evropskih držav, še posebej mladih, pomembno povečevala, ob tem pa se je zmanjševala verodostojnost jamstva, da višja stopnja formalne izobrazbe prinaša ustreznejšo in bolje plačano zaposlitev. Hkrati se spreminjajo prakse zaposlovanja, med drugim tudi zato, ker delodajalci vse pogosteje zahtevajo neformalno pridobljena znanja in veščine, ki so kratkoročno profitabilna, šolska spričevala in diplome pa pripoznavajo za vstopnico $v$ izbirni proces. Za zaposlitev so vse bolj relevantna neformalno pridobljena znanja in veščine, kot so: socialne in komunikacijske spretnosti, informacijska pismenosti, obvladovanja tujih jezikov idr. Od iskalcev zaposlitve se zahteva tudi sposobnost nadgrajevanja formalnih zanj in preusmerjanja od ozkih specifičnih $k$ širšim in splošnejšim kvalifikacijam. Učenje ob delu in učenje na dolgi rok oziroma vseživljenjsko učenje postajata del zaposlitve. Te nove zahteve na trgu dela še posebej prizadevajo populacijo mladih iskalcev prve zaposlitve. Kot kažejo raziskave, so mladi socialna skupina, ki je najpogosteje vključena v negotove oblike zaposlitve, kot so začasna in občasna dela, dela za določen čas, ki pogosto ne omogočajo izgradnje osebnih profesionalnih karier.

Prispevek obravnava dva problema, povezana s temi ugotovitvami: kako bi bilo mogoče ublažiti posledice dejavnikov, ki na trgu dela odrivajo mlade na družbeno margino, s poudarkom na individualnih vložkih v (dodatno) izobraževanje in vzpostavljaje socialnih omrežij; in ali bi mladi z najvišjimi stopnjami izobrazbe, kot tista skupina, pri kateri se z neustrezno zaposlitvijo izgubi največ znanja, z vlaganjem v človeški in socialni kapital lahko izboljšali svoje kompetence za uspešen prehod iz izobraževanja $v$ zaposlitev.

Ključne besede: zaposlovanje, mladi iskalci prve zaposlitve, trg dela, diplomanti na trgu dela, (ne)ustrezne zaposlitve, tržno nedeficitarne študijske usmeritve, človeški kapital, socialni kapital

\section{HOW TO GAIN ADDITIONAL KNOWLEDGE IN THE SITUATION WHEN UINIVERSITY DEGREES (NO LONGER) GUARANTEE SUITABLE EMPLOYMENT - »Profitability« of investment in social capital in highly educated job-seekers - ABSTRACT}

In the last decades the level of education of the European population, especially of the young, has risen significantly; however, the credibility of higher education as a guarantee of a suitable and well-paid employment has declined. Simultaneously, the employment practices have been changing, because, among other reasons, employers require increasingly often non-formally acquired knowledge and skills, which bring short-term profitability, whereas school records and university degrees are recognized only as entrance tickets into the selection process. Non-formally acquired knowledge and skills, such as social and communication skills, IT literacy, command of foreign languages, etc. are becoming more and more important in job search. In addition, job-seekers are required to have the ability to upgrade their formal knowledge and to move away from narrow, specific qualifications to the broader and more general. On-the-job learning and long-term learning - lifelong learning-are becoming an integral part of all jobs. These new labour market requirements are particularly hard on the segment of the young first-time job-seekers. And as research studies show, the young are the ones who make up the social group that is most frequently involved in non-secure types of employment, such as temporary or casual jobs and fixed-term employment. Low-security jobs often fail to give individuals the possibility to build up a personal professional career. The article deals with two issues related to the above-mentioned findings: - what to do to alleviate the consequences of the factors pushing the young to the margins of the society, emphasizing the need for investment in (additional) education and establishment of social networks; and, - whether the young who have acquired the highest levels of education (the group that loses most knowledge if doomed to an unsuitable career) could improve their ability to make a successful education-career transition by investing more in human and social capital.

Keywords: employment practices, young first-time job-seekers, labour market, the graduate on labour market, (un) suitable jobs, study courses for professions with a jobs deficit, human capital, social capital

UDK: 331.5 


\section{UVOD}

V zadnjih desetletjih se je izobraženost prebivalcev evropskih držav, še posebno mladih, pomembno povečevala, ob tem pa se je zmanjševala verodostojnost jamstva, da višja stopnja formalne izobrazbe prinaša ustreznejšo in bolje plačano zaposlitev. Kot kažejo podatki, v zadnjih dveh desetletjih najvišje stopnje izobrazbe ne zagotavljajo več varnosti pred brezposelnostjo in negotovimi oblikami zaposlitve, kar posebej velja za tiste iskalce prve zaposlitve, ki pridobijo certifikate na t. i. tržno nedeficitarnih študijskih usmeritvah. (Teichler, 2003.)

Spreminjajo se prakse zaposlovanja, med drugim tudi zato, ker delodajalci vse pogosteje zahtevajo neformalno pridobljena znanja in veščine, ki so kratkoročno profitabilni, šolska spričevala in diplome pa pripoznavajo kot vstopnico v izbirni proces. V postopkih izbire se preverjajo kompetence socialne in komunikacijske spretnosti, informacijska pismenost, interkulturna usposobljenost, obvladovanje tujih jezikov, ki jih formalna izobrazba nujno ne zagotavlja. Posebej poudarjajo sposobnosti hitrega dograjevanja znanj in veščin in preusmerjanja tako v okviru posameznih poklicnih spretnosti kot od ozkih specifičnih k širšim in splošnejšim kvalifikacijam. Učenje ob delu in učenje na dolgi rok oziroma vseživljenjsko učenje postajata del zaposlitve.

Podatki o gibanjih zaposlovanja in brezposelnosti govorijo o tem, da so mladi, ki stopajo na trg delovne sile in iščejo prvo zaposlitev, kljub boljši izobraženosti socialna skupina $\mathrm{z}$ najbolj oteženim dostopom do delovnih mest. Mladi so tudi socialna skupina, ki je najpogosteje vključena v negotove oblike zaposlitve, kot so začasna in občasna dela, dela za določen čas, zaposlitve za skrajšan čas, in te pogosto ne omogočajo izgradnje osebne kariere. Takšno stanje delno pojasnjuje pomanjkanje tistih znanj in veščin pri mladih, ki jih je mogoče pridobiti z delovno prakso.
Trend »podcenjenosti« formalne izobrazbe na trgu dela je sprožil vrsto raziskovanj, ki se že dobro desetletje ukvarjajo s problematiko prehoda mladih iz izobraževanja $\mathrm{v}$ zaposlitev. Ne najbolj množičen in tudi ne najbolj akuten, pač pa raziskovalno zelo zanimiv primer je kohorta visoko izobraženih iskalcev prve zaposlitve, ki bodisi v daljšem obdobju ne najdejo dela bodisi se zaposlijo na t. i. neujemajočih in/ali fle-

Učenje ob delu in
vseživljenjsko uče-
nje postajata del
zaposlitve.
ksibilnih delovnih mestih. Očitno je namreč, da je lahko naložba v pridobitev akademskega znanja in diplome tržno nerentabilna, postopki in instituti za njihovo pridobitev pa se ne morejo ustrezno prilagajati hitrim globalnim spremembam in njihovim posledicam na trgu dela. Naraščajoče število brezposelnih ali neustrezno zaposlenih mladih z najvišjimi izobrazbenimi certifikati je postavilo pod vprašaj nekatere predpostavke, ki so do nedavnega veljale za paradigmatične, denimo koncepta učeče se družbe (Hutchins, 1969) in družbe znanja (Delanty, 2001).

Rezultati raziskav o prehodu mladih izobraženih kadrov v ustrezno zaposlitev že dobro desetletje kažejo, da se deleži brezposelnih diplomantov povečujejo, da se sicer razlikujejo po posameznih državah (v EU) in da je stopnja brezposelnosti nesorazmerna glede na študijske usmeritve diplomantov. Vendar se obseg t. i. tržno nedeficitarnih študijskih usmeritev širi in vse več mladih diplomantov je prisiljenih zaposliti se na fleksibilna in neujemajoča delovna mesta. Razlike med spoloma glede na te ugotovitve so signifikantne, in to v škodo žensk.

Vse do pred kratkim so se raziskovalci problematike prehoda mladih iz izobraževanja $\mathrm{v}$ zaposlitev lotevali predvsem z eksplanativnimi študijami stanj in trendov na podlagi statističnih in javnomnenjskih podatkov (npr. Müller and Shavit, 1998), v zadnjem desetletju pa so se osredotočili tudi na mlade iskalce zaposlitve kot na primarni subjekt raziskovanja (npr. 
Teichler in drugi, CHEER, 1998-2000). Takšna, z zornega kota podzaposlenih mladih izhajajoča raziskovalna perspektiva, je odprla vrsto vprašanj in med pomembnejšimi so tista o možnostih ter sposobnostih (samo)aktiviranja in (samo)vlaganja študentov ter diplomantov $\mathrm{v}$ vire, ki v spremenjenih tržnih razmerah omogočajo ustreznejšo in hitrejšo zaposlitev. Vzporedno sta na ravni teoretske refleksije pridobila pomen koncepta človeškega in socialnega kapitala, ki kompleksno in pretežno pozitivno osmišljata individualna in družbena formalnemu izobraževanju dopolnilna vlaganja.

$\mathrm{V}$ prispevku izhajamo iz predpostavke, da je problem brezposelnosti in/ali neustrezne zaposlitve še posebno zanimiv pri diplomantih, ki so vložili največ v priprave za zaposlitev in profesionalno kariero. Namreč, izgube, ki nastanejo, ko ne dobijo ustreznega dela, niso le individualne, temveč prizadenejo tudi različne strukturne družbene ravni.

V prvem delu prispevka so predstavljeni pogledi na dejavnike, ki vplivajo na zaposlovanje mladih (diplomantov) s poudarkom na povezavah med izobraževalnim in zaposlovalnim sistemom ter trgom dela. V nadaljevanju postavljamo raziskovalno vprašanje, ali je mogoče nesinergetično delovanje teh treh subsistemov vsaj delno kompenzirati z (dodatnimi) vlaganji v socialni kapital. V podporo tej možnosti navajamo rezultate nekaterih novejših raziskav in študij. V zadnjem poglavju dokumentiramo zgornje vprašanje s podatki raziskave Evalvacija naložb v izobrazbeni kapital in mladinski trg dela, ${ }^{1}$ ki se poglobljeno ukvarja z ekonomskimi, socialnimi in osebnostnimi vidiki poti zaposlovanja slovenskih študentov in diplomantov tržno nedeficitarnih študijskih usmeritev.

\section{DEJAVNIKI, KI VPLIVAJO NA ZAPOSLOVANJE MLADIH}

Poleg dejavnikov, ki na splošno prepoznani ravni vplivajo na zaposlovanje (mladih), kot so: gospodarske in demografske spremembe, globalizacija trgov dela in posledično spremembe razmerij med ponudbo in povpraševanjem; novosti v procesih izbire in vrednotenja kandidatov za zaposlitev; spremenjene značilnosti delovnih mest; zaostrena konkurenčnost na posameznih profesionalnih trgih idr., se vse bolj izpostavljajo sklopi različnih dejavnikov kot multiplih agensov, ki pomembno določajo trende na področju zaposlovanja. Gangl (2001, v: Ivančič, 2010: 23) na primer ločuje strukturne in aktivnostne trende, ki vplivajo na procese zaposlovanja, in v tem kontekstu poudarja sile krčenja in ekspanzije tako ponudbe kot povpraševanja na trgu dela ter distributivne spremembe, ki vplivajo na razpoložljivo ponudbo kandidatov za zaposlitev. Katerakoli od sprememb teži $\mathrm{k}$ povečanemu tveganju brezposelnosti, in to za skupine najmanj tržno konkurenčnih iskalcev zaposlitve. Kot poudarja A. Ivančič (2010: 24), je pričakovati, da se bo tveganje brezposelnosti za iskalce prve zaposlitve povečevalo, vključno s preostalimi, ki nimajo delovnih izkušenj, kot tudi za slabo izobražene. Prihajalo bo do »izpodrivanja manj izobraženih kategorij z bolj izobraženimi « kot tudi do izpodrivanja $\mathrm{v}$ obratni smeri (prav tam).

Proučevanja uspešnosti prehoda iz izobraževanja v zaposlitev in vmesnega obdobja vključenosti mladih $\mathrm{v}$ trg dela postavljajo kot ključni sklop dejavnikov v mehanizmih vrednotenja izobrazbenih dosežkov naslednje: institucionalno ureditev trga dela; organiziranost izobraževalnega sistema; povezave med njima in ukrepe socialne države $\mathrm{v}$ podporo njuni učinkovitejši integraciji (Müller in Shavit, 1998). Po mnenju Garonna in Ryana (1989, v: Ivančič, 2010: 33) organizacijo trga dela simbolizirajo razmerja med mednarodnimi trgi, poklicnimi ter neorganiziranimi in naključnimi trgi dela. Pomembne pa so tudi razmere na področju delovnih razmerij, kolektivnih pogodb; običaji in prakse na delovnih mestih ter povezave med sistemi izobraževanja in delodajalci. Glede na te dejavnike je mogoče razlikovati tri modele vključevanja mladih na trg dela: 
- regulirano vključevanje v okviru dominantnih poklicnih trgov, pri katerem socialni partnerji neposredno nadzorujejo poklicno izobraževanje;

- selektivno izključevanje, pri katerem si delodajalci prizadevajo zagotoviti visoko dobičkonosnost $\mathrm{z}$ ohranjanjem dobro usposobljenih delavcev; po tem modelu obstaja večja verjetnost, da so »novoprišleki« razporejeni na položaje z najnižjimi kvalifikacijskimi zahtevami in v nestabilna delovna razmerja, kar povečuje možnosti, da se bodo mladi zaposlovali na sekundarnem trgu na nestabilnih delovnih mestih;

- in tretji model, ki je kompetitivna regulacija, s katero si delodajalci zaradi pritiska ekonomskega okolja ali zaradi neravnotežja med ponudbo in povpraševanjem prizadevajo doseči dobičkonosnost delovne sile na kratek rok.

Vloga in pomen začetnega izobraževanja se spreminjata od enega do drugega regulacijskega sistema (Couppié, Mansuy, 2001, v: prav tam: 35). Standardi poklicnih kvalifikacij, ki jih določajo vsi ključni akterji na trgu dela (delodajalci, sindikati, država), predstavljajo komponento reguliranega sistema vključevanja in pogoje za dostop do različnih poklicnih trgov. In to ob pričakovanjih, da so definicije kvalifikacij blizu zahtevam po znanjih in spretnostih, ki jih postavljajo delodajalci. Mladinske kvalifikacije bi morale vključevati tudi pripravo na svet dela in življenje $\mathrm{v}$ podjetju, tudi $\mathrm{v}$ formalni povezavi $\mathrm{z}$ izobraževanjem (vajeništvo, obdobje prakse).
Tako kot v vseh drugih evropskih državah tudi v Sloveniji delodajalci zaradi pritiska globalne konkurence težijo k povečevanju kratkoročne učinkovitosti delovne sile prek zagotavljanja večje prožnosti delovanja trga dela. Prihaja do postopne deregulacije, ki se kaže predvsem v zniževanju stroškov odpuščanja zaposlenih in zmanjševanju omejitev pri uporabi fleksibilnih oblik zaposlitve, ki so jim po razpoložljivih podatkih najbolj podvrženi prav mladi iskalci prve zaposlitve.

Pogostost menjave delovnega mesta, značilna za mlade iskalce zaposlitve, se stopnjuje tudi v Sloveniji, prav tako neujemajoče in fleksibilno zaposlovanje, ki omejuje izgradnjo profesionalne kariere. Tudi raziskave opozarjajo na negativne posledice hitre menjave zaposlitve, še zlasti pri mladih, ki so $\mathrm{k}$ temu prisiljeni (Bernhard in drugi, 2000). S prepogosto menjavo zaposlitve in/ali s prehajanjem iz eno $\mathrm{v}$ drugo nestabilno zaposlitev mladi ne napredujejo.

Izobraževalne institucije tako v Sloveniji kot v drugih evropskih državah si sicer prizadevajo »ujeti korak «s spremembami v procesih zaposlovanja (Teichler, 2004), so pa v teh prizadevanjih le delno uspešne. Primanjkljaj v njihovem prilagajanju vodi $v$ širitev kroga t. i. tržno nedeficitarnih študijskih smeri, ki ne le povečujejo »produkcijo« brezposelnih ter neustrezno ali/in začasno zaposlenih diplomantov, temveč jih tudi »opremljajo« z znanji, ki jim, razen vstopnega certifikata, ne bodo omogočala izobrazbi ustrezne zaposlitve in profesionalne kariere. ${ }^{2}$ To razhajanje posamezne univerze

Če poskušamo umestiti Slovenijo v enega od obravnavanih modelov integracije mladih na trg dela in če pri tem upoštevamo značilnosti izobraževalnega sistema ter institucionalne ureditve trga delovne sile, lahko sklepamo, da prevladuje model regulirane integracije. V slovenskem izobraževalnem sistemu se izobrazbene kvalifikacije formalno oblikujejo ob intenzivnem sodelovanju partnerjev na trgu delovne sile. Kvalifikacije, pridobljene v formalnem izobraževanju, so standardizirane na nacionalni ravni in so zasnovane tako, da omogočajo poklicno mobilnost in napredovanje $\mathrm{v}$ poklicni karieri. Kljub temu se tudi na slovenskem trgu dela povečujejo razlike med formalno usposobljenostjo visoko izobraženih kandidatov za zaposlitev in zahtevami zaposlovalcev po že opisanih dodatnih znanjih, ki jih formalno izobraževanje ne omogoča. 
in fakultete premoščajo z občasnimi in skrajšanimi izobraževalnimi programi, s katerimi poskušajo študente »opremiti« $\mathrm{s}$ temeljnimi veščinami, potrebnimi za kompetenten vstop na trg dela in vključitev $\mathrm{v}$ postopke iskanja Mladi se na spremembe na trgu dela odzivajo s prilagajanjem karierne poti.

zaposlitve. Nekatere si prizadevajo vzpostaviti tudi omrežja s potencialnimi delodajalci za »svoje « diplomante. Za zdaj pa še ne obstaja študija uspešnosti teh prizadevanj, niti za Slovenijo niti za Evropsko unijo.

Mladi iskalci zaposlitve, še posebno visoko izobraženi, se na spremembe na trgu dela odzivajo s prilagajanjem karierne poti. Od konca 80. let se pojmovanje tradicionalne kariere zamenjuje $\mathrm{s}$ sodobnimi koncepti, ki postavljajo v ospredje posameznike, ki svojo kariero oblikujejo neodvisno od organizacije (Arthur in Rousseau, v Podmenik, Černigoj Sadar, 2008), in to $\mathrm{Z}$ multipnostjo karier, lateralnimi (ne vertikalnimi) kariernimi premiki, prekinjenimi in vzporednimi kariernimi potmi, kar je mogoče spremljati tudi v Sloveniji. S tako spremenjenimi kariernimi usmeritvami so povezani tudi premiki v oblikah in načinih izobraževanja. Z v preteklosti široko razširjenim izobraževanjem ob delu, ki je večinoma pomenilo »doizobraževanje« za dosego delovnemu mestu ustreznega certifikata, je mogoče danes primerjati t. i. učenje iz dela (»on job learning «). Nekoč razširjene kadrovske štipendije danes (vsaj deloma) nadomeščajo oblike tutorstva znanjsko zahtevnih zaposlovalcev, ki izvajajo nabor potencialnih kadrov tudi že $\mathrm{v}$ osnovnih šolah, vsekakor pa med srednješolskim in visokošolskim izobraževanjem. Izbrane kandidate občasno vključujejo $\mathrm{v}$ delovne procese prek učnih in študijskih praks ter jih doizobražujejo in specializirajo za konkretna delovna mesta. ${ }^{3}$ Takšne, s podporo potencialnih zaposlovalcev načrtovane specializirane in enosmerne karierne usmeritve pa so med diplomanti v manjšini, še posebej med tistimi, ki so zaključili študij na tržno nedeficitarnih študijskih smereh. Omenili smo že, da se povečujeta tako število brezposelnih diplomantov kot obseg študijskih usmeritev, ki »producirajo« potencialno nezaposljive diplomante. Trojček kazalcev, s katerim lahko prikažemo (ne)deficitarnost posameznih študijskih usmeritev, kaže: prvič, v Sloveniji so bile v obdobju 1998-2005 največje rasti deleža diplomantov ugotovljene na naslednjih študijskih področjih: storitve (407 odstotkov), družboslovje (283 odstotkov), kmetijstvo (248 odstotkov) ter zdravstvo in socialno skrbstvo (241 odstotkov) (SURS, 2006); drugič, nesorazmerja med vpisanimi študenti in zaposlenimi diplomanti so bila največja na področju kmetijstva, humanističnih ved, družboslovja in izobraževanja; in tretjič, rast števila registriranih brezposelnih diplomantov v obdobju 2005-2009 je bila največja na področju zdravstva in socialnega skrbstva (86 odstotkov), izobraževanja (49 odstotkov), humanističnih ved (25 odstotkov) in menedžmenta (20 odstotkov) (ZZRS, 2010). Na podlagi teh podatkov je mogoče sklepati, da se v skupino tržno nedeficitarnih študijskih področij uvrščajo: družboslovje, humanistika, izobraževanje, kmetijstvo, zdravstvo in socialno skrbstvo ter v zadnjem času tudi menedžment. Poleg neenakih možnosti za ustrezno zaposlitev, pogojenih z izbiro študijskega področja oziroma študijske usmeritve, se karierne in poklicne perspektive študentov in diplomantov razlikujejo tudi zaradi »klasičnih« socialnih neenakosti. Kot ugotavljata Schomburg in Teichler (prav tam), socialne razlike niso izginile niti pri dostopnosti visokošolskega študija, niti pri študijskih rezultatih, niti pri možnostih za pridobitev ustrezne zaposlitve. ${ }^{4}$

\section{SOCIALNI KAPITAL - MEDIATOR MED (VISOKIM) IZOBRAŽEVA- NJEM IN ZAPOSLITVIJO?}

Kot smo že omenili, se v novejših študijah o prehodu mladih iz izobraževanja na trg dela socialni kapital obravnava kot pomemben dejav- 
nik, ki ob študijskih dosežkih lahko pripomore k boljšim možnostim zaposlovanja mladih, vključno tistih z najvišjimi stopnjami izobrazbe. $\mathrm{V}$ zadnjem desetletju se je koncept socialnega kapitala uveljavil kot eden najpomembnejših diskusijskih vsebin v različnih kontekstih družboslovnega diskurza. Kljub temu pa ni prišlo do splošnega konsenza o temeljnih predpostavkah in načinih operacionalizacije glavnih kazalcev tega koncepta. Kot ugotavljata Grootaaert in Bastelaar (2002: 341), je koncept socialnega kapitala utemeljen in obdelan do ravni, na kateri je bil človeški kapital pred 30 leti. Večina avtorjev se strinja, da sodobne konceptualizacije socialnega kapitala temeljijo na treh virih: teoretičnem in empiričnem delu Bourdieuja (1985), Colemana (1988) in na teoriji omrežij (Burt, 2001, v: Adam, Rončevič, 2003: 160). Tako Bourdieu kot Coleman povezujeta socialni kapital s človeških kapitalom oziroma $\mathrm{z}$ izobraževanjem in izobraževalnimi ter učnimi dosežki.

Tako kot »klasični « tudi sodobni avtorji obravnavajo povezanost obeh konceptov. Dika in Singh (2002) sta v 14 študijah proučevala odnos med socialnim kapitalom in izobraževalnimi dosežki in $\mathrm{v}$ večini proučevanih primerov odkrila pozitivne povezave. Ugotovila sta tudi pozitivno korelacijo med izobraževalnimi dosežki proučevanih subjektov in socialnim kapitalom njihovih staršev.

Sodobne študije odkrivajo tudi bolj posredne povezave med tema kapitaloma, tako denimo ena od njih ugotavlja pozitivno korelacijo med učenjem v skupnosti in študijskimi dosežki slovenskih študentov (Vidovič, 2003: 178-181).
Broth (2002) ob proučevanju komunikacijskih omrežij ugotavlja, da se samozavest študentov in zaupanje $\mathrm{v}$ pozitivne študijske dosežke razvijata s pogovori o študentskih in študijskih tematikah, in to z različnimi osebami, starši, kolegi, administrativnim osebjem, profesorji, sosedi idr. Samozavest in zaupanje $\mathrm{v}$ študij pa pripomoreta k boljšim študijskim dosežkom ter $\mathrm{k}$ ustreznejšim in zadovoljivejšim socialnim odnosom. Študijsko uspešnejši so tisti študenti, ki aktivno participirajo $\mathrm{v}$ akademskih dejavnostih,
Socialni in cloveški kapital ter izobraževalni dosežki so $\mathrm{v}$ pozitivni korelaciji. recimo redno obiskujejo predavanja in druge obvezne dejavnosti.

Glede pomena socialnih omrežij pri pridobivanju zaposlitve študije dokazujejo, da je iskanje zaposlitve prek neformalnih socialnih vezi pogosto uporabljena metoda tako v Evropi kot $\mathrm{v}$ ZDA in jo uporabljajo tako iskalci zaposlitve kot zaposlovalci (Pellizzari, $2004^{6} \mathrm{v}$ : Ponzo in Scoppa, 2009). Ob tem pa Ponzo in Scoppa ugotavljata, da se na italijanskem trgu dela ta omrežja pogosteje uporabljajo med nizko izobraženimi iskalci zaposlitve in da so zaposlitve, pridobljene s to metodo, slabše kakovosti in slabše plačane. Po njunem mnenju morajo biti raziskovalci v empiričnih študijah posebno pozorni na pomembne razlike med $»$ profesionalnimi $\ll$ in »familiarnimi « povezavami. Kajti v študijah, ki proučujejo profesionalne kontakte kot kanale za pridobitev zaposlitve, so rezultati neformalnega mreženja pozitivni (merjeni s plačo na pridobljenem delovnem

Na ravni interakcij med družbenimi sferami je ugotovljeno, da ima socialni kapital pomembno vlogo pri prenosu znanja iz akademskega v gospodarsko okolje. Človeški kapital na drugi strani ne omogoča ustreznih interakcij med tema dvema okoljema (Lenarčič, 2008). Posamezniki, ki prehajajo z akademskega na gospodarsko področje, potrebujejo ob visoki formalni izobrazbi tudi usposobljenost za timsko delo, obvladati morajo komunikacijske spretnosti in imeti izkušnje z vzpostavljanjem in razširjanjem socialnih omrežij. Kot sta ugotovila Adam in Rončević (2003: 175), je mogoče socialni kapital definirati kot katalizator v procesu diseminacije človeškega in intelektualnega kapitala, saj obstoj in vzdrževanje različnih socialnih omrežij, ki temeljijo na zaupanju, recipročnosti in kooperativnosti, vzpostavlja most med akademsko in drugimi družbenimi sferami, vključno s trgom dela in gospodarsko sfero. 
mestu); rezultati študij, ki proučujejo pomoč znancev, prijateljev in družinskih članov pri pridobivanju zaposlitve, pa dajejo negativne rezultate (izražene z enako merilno enoto).

Rezultati študij v primerih proučevanja formalnih socialnih omrežij kažejo, da vključevanje vanje, denimo aktivna participacija ali članstvo $\mathrm{v}$ prostovoljnih združenjih, pozitivno vpliva na pridobitev ustrezne zaposlitve (Degli Antoni, 2009). Avtor poudarja, da so socialna omrežja in človeški kapital pomembni viri, ki jih brezposelni pridobijo s participacijo $\mathrm{v}$ prostovoljnih združenjih, in bistveno povečujejo možnosti zaposlitve.

\section{VLAGANIA V SOCIALNI KAPITAL IN DODATNO IZOBRAŽEVANJE - PRIMER SLOVENSKIH ŠTUDENTOV}

Ali sploh, koliko in kako učinkovito - glede na izboljšanje možnosti za pridobitev ustrezne zaposlitve po diplomi - slovenski študenti vlagajo v socialni kapital in dodatno izobraževanje? Pri iskanju odgovorov si lahko pomagamo s podatki, delno tudi iz eksplorativne raziskave o naložbah v visokošolsko izobraževanje, ${ }^{7}$ izvedene na namensko izbranem vzorcu študentov $^{8}$ v študijskem letu 2004/2005 (Podmenik, Černigoj Sadar, Ivančič, 2006).

\section{Vlaganja $v$ dodatne študijske dejavnosti in neformalno izobraževanje}

Tako rezultati omenjene raziskave kot podatki raziskave Evroštudent $(2005)^{9}$ kažejo, da obe vzorčni populaciji študentov načrtno vlagata $v$ formalne študijske obveznosti; redno se udeležujeta predavanj in vaj (vsakodnevno ali večkrat na teden). Večina jih tudi ustrezno samostojno študira (več kot polovica vsak dan ali nekajkrat na teden). Za slabo petino je mogoče trditi, da študira kampanjsko. Zanimivo je, da je dokaj razširjen tudi skupinski študij.

V primerjavi z rednimi študijskimi dejavnostmi pa podatki obeh raziskav kažejo neustrezno participacijo v tistih študijskih dejavnostih, ki niso neposredno vključene $\mathrm{v}$ redni program študija (druga predavanja na fakulteti, simpoziji in okrogle mize, ekskurzije). Pomembno je poudariti nezadostno zanimanje za študij $\mathrm{v}$ tujini; po podatkih Evroštudent je v letu 2004 s študijskimi nameni obiskalo tujino in/ali bivalo v tujini le 9,3 odstotka anketiranih, trije odstotki vprašanih je v tujini opravilo obdobje študija (vpis) in le 14,3 odstotka vprašanih ima resen namen obiskati tujino in/ali bivati $\mathrm{v}$ tujini.

Primerjava vložkov v obštudijske dejavnosti in izobrazbe staršev kaže, da najpogosteje obiskujejo tujino, simpozije, okrogle mize in dodatna predavanja študenti, katerih starši imajo srednjo in visoko izobrazbo, najmanj pa tisti, katerih starši imajo nižjo izobrazbo.

Vlaganja študentov iz vzorca zgoraj omenjene raziskave $\mathrm{v}$ neformalno pridobivanje znanj so prikazana v Tabeli 1.

Kot kaže tabela, se le slaba tretjina anketiranih študentov pogosto ukvarja $\mathrm{z}$ dejavnostmi, ki dopolnjujejo njihov študij, in išče informacije prek interneta, le približno četrtina

\begin{tabular}{|c|c|c|c|c|c|c|c|}
\hline \multirow{2}{*}{$\begin{array}{l}\text { Tabela 1: Vložki v dodatno } \\
\text { izobraževanje in delo }\end{array}$} & \multirow{2}{*}{ Nikoli } & \multirow{2}{*}{ Redko } & \multirow{2}{*}{ Občasno } & \multirow{2}{*}{ Pogosto } & \multirow{2}{*}{$\begin{array}{c}\text { Zelo } \\
\text { pogosto }\end{array}$} & \multicolumn{2}{|c|}{ Skupaj } \\
\hline & & & & & & & $\mathrm{N}$ \\
\hline Delo, s katerim služim denar & $23 \%$ & $20 \%$ & $19 \%$ & $17 \%$ & $21 \%$ & $100 \%$ & 149 \\
\hline S prostovoljnim delom dopolnjujem znanje & $35 \%$ & $28 \%$ & $24 \%$ & $7 \%$ & $6 \%$ & $100 \%$ & 149 \\
\hline Študijska praksa & $16 \%$ & $18 \%$ & $28 \%$ & $19 \%$ & $18 \%$ & $100 \%$ & 146 \\
\hline Iščem stike $\mathrm{z}$ osebami in institucijami & $11 \%$ & $32 \%$ & $32 \%$ & $17 \%$ & $8 \%$ & $100 \%$ & 149 \\
\hline Dejavnosti, ki dopolnjujejo moj študij & $11 \%$ & $32 \%$ & $25 \%$ & $21 \%$ & $11 \%$ & $100 \%$ & 150 \\
\hline Prebiram literaturo, se seznanjam prek interneta & $8 \%$ & $36 \%$ & $24 \%$ & $10 \%$ & $22 \%$ & $100 \%$ & 50 \\
\hline
\end{tabular}


pa načrtno razširja možnosti za pridobitev novih veščin in socialnih stikov zunaj študijskih obveznosti. Študijska praksa, ki je obvezna študijska dejavnost, hkrati pa tudi oblika izobraževanja iz dela, je seveda dobro »obiskana « in tako (še vedno) ostaja ena redkih oblik sodelovanja študentov s potencialnimi zaposlovalci, ki odpira možnosti vzpostavljanja profesionalnih omrežij in je korak na poti izgrajevanja kariere. Na splošno je mogoče ugotoviti, da respondenti to dvoje večinoma prepuščajo naključju.

Tako podatki iz Tabele 1 kot podatki raziskave Evroštudent kažejo, da študenti v času študija opravljajo različna dela. Le manjšina pa ima to srečo, da delajo na področjih, na katerih se tudi izobražujejo, ali pa vsaj na študiju »sorodnih « področjih. Oceniti je mogoče, da delo, ki ga študenti v večini opravljajo redno, ni povezano niti z njihovim študijem niti ni $\mathrm{v}$ podporo njihovi profesionalni karieri. To potrjuje tudi podatek, ki kaže, da se vprašani o svojih načrtih in aspiracijah za prihodnost $\mathrm{v}$ okoljih, kjer občasno delajo, ne pogovarjajo niti $\mathrm{z}$ delodajalci niti s sodelavci, kar navaja na sklep, da se prek študentskega dela ne zaposlujejo v dejavnostih, ki podpirajo študij ali profesionalno pot. Vendar je kljub temu mogoče govoriti o določenih oblikah t. i. učenja iz dela; vsi vprašani namreč omenjajo, da so si tudi z opravljanjem priložnostnih del nabirali pomembne izkušnje in znanja, če ne drugega, pa veščine (so)delovanja $\mathrm{z}$ zaposlovalci in obvladovanja administrativnih procedur.

In kaj so o vlaganjih $\mathrm{v}$ dodatno pridobivanje znanja povedali diplomanti na trgu dela? Povzeti je mogoče, da intervjuvani diplomiranci selektivno vlagajo $\mathrm{v}$ dodatne oblike pridobivanja znanj. Na primer diplomirani politolog Vlado, ki pravi:

... bi rekel, da sem šel pri večini predmetov po liniji najmanjšega odpora, pri tistih temah, ki so me bolj zanimale, sem pa ogromno delal, mislim, ogromno več, kot je bilo predvideno $v$ učnem načrtu, recimo $z$ ogromno druge literature ... sem delal tudiv tujini na teh zadevah, ki so me zanimale, in sem potem to kombiniral s študijem.

Od intervjuvanih sta dve osebi študirali v tujini, ena je tam tudi iskala delo, pa ni imela dobrih izkušenj, predvsem zaradi neurejenega sodelovanja med Slovenijo in sosedsko državo. Velika večina intervjuvanih ne omenja zaposlitve v tujini kot možnosti za rešitev problema zaposlitve. Intervjuvanka, ki je študirala v tujini, pravi:

$V$ tujini sem že študirala ... ne vem, takrat sem bila še premlada, pravzaprav nisem bila ravno prepričana, da želim tam ostati ... nisem znala jezika, to je tak precej zakompliciran jezik, na ta način kot slovenščina ... pa država, recimo D., ni zelo odprta država. Sem se potem nekako odločila, da se vrnem domov ... Res, že tako je težko, ampak v tujini je pa vse še dvakrat, trikrat težje. (Maja)

Vsi intervjuvani se po diplomi ukvarjajo $\mathrm{z}$ iskanjem ustreznega dela, tudi tisti, ki so že začasno zaposleni, in tisti, ki nadaljujejo študij. Poti iskanja so podobne, večina jih ima izkušnje z zavodom za zaposlovanje, prek katerega so opravljali različna začasna dela, pogosto so omenjana tudi javna dela. Dela z njihovih študijskih področij niso pogosta, a po oceni respondentov (podobno kot anketiranih študentov) tudi druga prinašajo določena znanja. Alja, diplomantka kadrovskega menedžmenta, ugotavlja:

Ja, na zavod za zaposlovanje sem se prijavila, razpise gledala, a ne ... Delo, internet, hodiš na razgovore, takšne in drugačne, odgovarjajo ti, ali pa ne ... sem kar pošiljala prošnje, $v$ bistou sem jaz takrat kar hitro dobila prek javnih del zaposlitev ... V glavnem sem bila recimo poslovni sekretar in sem delala vse ... Pol pa po enem letu javna dela potečejo, malo so mi še podaljšali, pol pa sem bila spet na zavodu ... To hočem reči, da vsako delo, ki ga sprejmeš, pa tudi za nižjo stopnjo pa nižjo plačo, ti lahko nekaj prinese. 


\section{Vlaganja $v$ socialni kapital}

Eden od kazalcev vlaganj v socialni kapital so komunikacijska omrežja in koristnost vsebine komunikacij. Rezultate o »profesionalnih« komunikacijskih omrežjih respondentov iz raziskave (Podmenik in drugi, 2006) kaže Tabela 2. Vprašani študenti imajo redne stike predvsem s kolegi in prijatelji. S profesorji in mentorji ima redne stike le slaba tretjina, večina pa le redko ali ob posebnih dogodkih. Čeprav je 88 odstotkov anketirancev pogosto ali zelo pogosto vključenih v različna dela, jih tretjina nikoli in več kot polovica le redko ali ob posebnih dogodkih govori o svojem študiju in karieri v delovnem okolju. T. i. profesionalno komunikacijsko omrežje anketiranih študentov lahko ocenimo za šibko. Presenečajo šibke povezave med profesorji in študenti. Sklepati je mogoče, da vprašani ne izgrajujejo svojih socialnih omrežij načrtno, saj so ta pretežno omejena na ozek krog kolegov.

Podobne rezultate je mogoče razbrati tudi iz intervjujev z diplomiranci, katerih večina je povedala, da socialnih stikov niso vzpostavljali namensko oziroma načrtno, s cilji odpiranja poti za profesionalno kariero ali odpiranja možnosti za zaposlitev. Prepoznali pa so socialne povezave za pomembne, še posebno pri iskanju zaposlitve. Kot je razvidno iz pripovedi Mire, diplomantke Filozofske fakultete, intervjuvani prepoznavajo tudi pomembnost politične opredelitve pri možnosti za vzpostavljanje socialnih mrež:

Seveda so bili (socialni vložki pomembni, op. a.) ... in da so pravzaprav vedno bolj.

Žal pa je tako in to je zelo pomembno $v$ bi- stou,... kateremu delu prostora pripadaš ... Pač kam politično sodiš. To je zelo pomembno, čeprav ti sam se ne opredeljuješ ... jaz osebno se ne opredeljujem, še zlasti ne, ko sem bila mlajša ... A je pač tako, da če se ti ne opredeljuješ, te pa drugi opredelijo. Meni je bilo pomembno predosem, da delam, da dobro in kakovostno delam.

In o načrtnem tkanju socialne mreže:

$\mathrm{Ne}$, nisem tako preračunliviva ... ne, meni je bila pomembnejša sama vsebina. Sem pač povezana z ljudmi, s katerimi nas družijo podobni problemi, interesi, in se mi je zdelo... tako, pač strokovnjaki na svojem področju... Pravzaprav je bil to edini fokus, tako bom rekla. In od tam naprej je pravzaprav vse sledilo. (Maja)

Če se spomnimo ugotovitve Ponza in Scoppa (2009) o pomembnosti izgrajevanja profesionalnih omrežij za iskanje primerne zaposlitve, lahko ugotovimo, da proučevanim aktualnim in bodočim visoko izobraženim iskalcem zaposlitve močno primanjkuje tega vira socialnega kapitala.

Podatki kažejo, da tudi drugi kazalec socialnega kapitala - vlaganja v izgradnjo kariere - ni deležen primerne pozornosti in naporov vzorčnih slovenskih študentov.

Večina vprašanih sicer pogosto ali zelo pogosto razmišlja o tem, kaj želijo postati, skoraj vsi pa o tem, kako bi se materialno osamosvojili. Toda tretjina jih ne ve, kaj bodo počeli po diplomi, slaba tretjina pa namerava študij nadaljevati. Petintrideset odstotkov jih ima izdelan načrt, kako bi se zaposlili, dobra četrtina pa ima le zamisli o tem.

\begin{tabular}{|c|c|c|c|c|c|c|c|}
\hline \multirow[t]{2}{*}{ Tabela 2: Socialni vložki } & \multirow{2}{*}{ Nikoli } & \multirow{2}{*}{ Redko } & \multirow{2}{*}{$\begin{array}{l}\text { Posebni } \\
\text { dogodki }\end{array}$} & \multirow{2}{*}{$\begin{array}{l}\text { Nekajkrat } \\
\text { na mesec }\end{array}$} & \multirow{2}{*}{$\begin{array}{c}\text { Večkrat na } \\
\text { teden }\end{array}$} & \multicolumn{2}{|c|}{ Skupaj } \\
\hline & & & & & & & $N$ \\
\hline Razprave s kolegi in prijatelji & $1 \%$ & $3 \%$ & $5 \%$ & $26 \%$ & $66 \%$ & $100 \%$ & 149 \\
\hline Razprave s profesorji, mentorii & $5 \%$ & $22 \%$ & $39 \%$ & $30 \%$ & $5 \%$ & $100 \%$ & 149 \\
\hline Pogovori o študiju z drugimi osebami & & $14 \%$ & $16 \%$ & $45 \%$ & $26 \%$ & $100 \%$ & 148 \\
\hline Pogovori o karieri z drugimi osebami & $1 \%$ & $24 \%$ & $18 \%$ & $42 \%$ & $14 \%$ & $100 \%$ & 149 \\
\hline Pogovori o študiju in karieri na delovnem mestu & $32 \%$ & $32 \%$ & $25 \%$ & $8 \%$ & $3 \%$ & $100 \%$ & 130 \\
\hline
\end{tabular}


Pomembna informacija o načrtih za prihodnost je, ali imajo vprašani pri tem vzorni$\mathrm{ka}$, in če ga imajo, ali so z njim v stiku. Več kot polovica vprašanih (58 odstotkov) nima vzornika in le manjšina (17 odstotkov) ima vzornika, s katerim navezujejo stike. Če večina študentov nima vzornika, pa se o svojih načrtih za prihodnost skoraj vsi (91 odstotkov) z nekom pogovarjajo. Izmenjava idej poteka predvsem med prijatelji in študijskimi kolegi; tudi s starši in partnerji, pri tistih, ki jih imajo. Zelo redko pa izmenjujejo mnenja z mentorji in vzorniki. Najbolj pogosto ostajajo sami pri razmišljanju o svojih načrtih študenti (15 odstotkov), katerih starši imajo nižjo izobrazbo. $Z$ večjim številom različnih oseb pa se pogosteje pogovarjajo študenti, katerih starši imajo visoko izobrazbo.

Zanimivo je, kako intervjuvani diplomanti ocenjujejo svoja vlaganja v izobraževanje po daljšem iskanju zaposlitve na mladinskem trgu dela. $\mathrm{O}$ »tržni vrednosti« vseh vložkov, se pravi, o primerjavi vložkov z »izkupičkom« na trgu dela, je večina intervjuvanih mnenja, da so vložili več, kot je njihova izobrazba vredna na trgu dela, oziroma, da so vložili (pre)veliko glede na težave s pridobitvijo zaposlitve. Glede pridobljenega znanja pa so ocene vlaganj bolj pozitivne.

Jah no, ja, v obliki znanja vsekakor sem dobila nazaj. Materialno pa pač ne, glede na to, da sem brezposelna. (Meta, dipl. kulturologinja)

Če zdaj pogledam, koliko sem dobil nazaj... potem so totalno previsoki stroški, ne. Glede na to, kar so me naučil, pa bi rekel, da so tako nekako realni ... neke vsebine bi mi pomagale, ampak sam bolj verjamem, da pač izkušnje ti nekaj dajo, izobrazba je pa več ali manj samo formalnost. (Rok, diplomant Fakultete za organizacijske vede)

Tudi kot osebnostno pridobitev, bodisi v obliki razgledanosti bodisi v obliki »osebnostne rasti«, intervjuvani pozitivno vrednotijo svoj študij in izobraževanje.
Ja ... kar se tiče moje osebnosti, pa osebne rasti, se mi zdi fajn, da sem šla to študirat, kar se pa tiče denarja, je pa to absolutno čista zguba, a ne. Ampak čutim, da mi bo nekoč to prišlo prav. (Miša, diplomantke filozofije in teologije)

\section{SKLEP}

Čeprav smo predpostavljali, da bodo podatki, pridobljeni na izbranem vzorcu študentov in diplomatov tržno nedeficitarnih študijskih usmeritev, pokazali:

- da se ti (že) zavedajo težav na trgu dela in v procesu pridobivanja ustreznih zaposlitev;

- da temu primerno vlagajo v dodatna (profesionalna) znanja in veščine;

- da vlagajo tudi v (profesionalna) socialna omrežja oziroma v socialni kapital in

- si prizadevajo za izgradnjo kariernih poti, to ne drži. Podatki, pridobljeni z anketo med študenti, kažejo, da študenti zadnjih letnikov družboslovnih in humanističnih usmeritev nimajo izdelanih načrtov o tem, kako in kje se bodo zaposlili. Večina se sicer pogovarja o svojih načrtih s svojimi kolegi, starši in partnerji. Mentorstvo pri načrtovanju kariere in zaposlitve jim je v večini tuje. Večina študentov poleg rednega študija tudi dela, vendar pretežno zaradi zaslužka, ki ga potrebuje za študij. Dodatno znanje in veščine si redno v različnih obštudijskih dejavnostih pridobiva le slaba tretjina študentov, enako velja za prebiranje dodatne literature in iskanje informacij prek interneta. Socialna omrežja vzpostavljajo spontano in pretežno v primarnih socialnih okoljih. Neustrezno zaposlovanje prek študentskega dela jim tudi ne omogoča vzpostavljanja profesionalnih omrežij v času občasnih zaposlitev kot tudi ne ustreznega učenja iz dela.

Sklenemo lahko, da ti študenti vstopajo na trg dela ne le diskriminirani zaradi študijske usmeritve, ki so si jo izbrali na začetku študija, temveč tudi zaradi nezadostnih vložkov v socialni in (dodatni) človeški kapital in ne 
nazadnje zaradi nezadovoljive seznanjenosti s težavami, s katerimi se bodo srečali pri iskanju (ustrezne) zaposlitve. Ob tem je treba omeniti, da tudi izobraževalci in zaposlovalci ne storijo dovolj, da bi te težave zmanjšali.

\section{LITERATURA IN VIRI}

Adam, F., Rončević, B. (2003). Socialni kapital: opredelitev in raziskovalne strategije (Social Capital: Definition and Research Strategies). Ljubljana: Sophia.

Adam, F. s sodelavci (2010). Lokalna in regionalna razvojna jedra. Zaključno poročilo o rezultatih raziskovalnega dela na aplikativnem projektu. Ljubljana, Nova Gorica: Inštitut IRSA, Fakulteta FUDŠ.

Bell, D. (1972). The Coming of Post-industrial Society. New York: Basic Books.

Bernhard, A., Morris, M., Handcock, M. S., Scott, M. A. (2000). Trends in job instability and wages for young men. V: Neumark, D. (ur.), On the job. Is long-term employment a thing of the past? New York: Russell Sage Foundation, 111-141.

Bourdieu, P. (1985). Distinction, a social critique of the judgement of taste. London, New York: Routledge\&Kegan Paul.

Broth, B. A. (2002). »Linking extracurricular Programming to Academic Achievement: Who benefits and Why? « Sociology of Education, 75: 69-91.

Coleman, J. S. (1990). Equality and Achivement in Education. Boulder: Westview Press.

Coleman, J. S. (1991). »Matching Process in the Labour Market«. Acta sociologica, 34: 3-12.

Couppié, T., Mansuy M. (2001). New Entrants and experinced workers on the Europen Labour Markets. Marseille: Cereque, Insee.

Degli Antoni, G. (2009). »Getting a Job through Voluntary Associations: the Role of Network and Human Capital Creation «. NEP - New Economic Paper: 10-17.

Dika, S. L., Singh, K. (2002). »Applications of Social Capital in Educational Literature: a critical synthesis«. Review of Educational Research, 72, 1: $31-60$.

Delanty, G. (2001). Challenging Knowledge, The University in Knowledge Society. Maidenhead: Open University Press.

Key Data on Higher Education in Europe. Education and Culture DG (2007). Brussels: EURYDICE.

Europe in Figures (2006/2007). EUROSTAT (Labour market, 146). Dostopno na: http://epp.eurostat. ec.europa.eu/portal/page/portal/product_details/ publication?p_product_code=KS-CD-07-001

Evroštudent (2005). Dostopno na: http://eurostudent. mvzt.gov.si

Field, J. (2003). Social Capital. London, New York: Routledge.

Gangl, M. (2003). The Only Way is UP? Employment Protection and Job Mobility among Recent Entrants to European Labour Markets. V: Kogan, I., Müller, W. (ur.), School to Work Transition in Europe: Analysis of EU LFS 2000 Ad Hoc Module. Mannheim: MZES.

Garonna, P., Ryan, P. (1989). »Le travail des jeunes, les relations professionelles et les politiques sociales dans les économies avancées «. Formacion Emploi, 25.

Grotaaert, C., Bastelaar, T., ur. (2002). The Role of Social Capital in Development. Cambridge: University Press.

Interni podatki o registrirani nezaposlenosti (2010). Ljubljana: Zavod Republike Slovenije za zaposlovanje.

Ivančič, A. (2010). Spremembe na trgu delovne sile, pomen izobrazbe in pismenost zaposlenih. Ljubljana: Inštitut IRSA.

Hutchins, R. (1969). The Learning Society. New York: Frederick A. Praeger.

Kerckhoff, A. C. (2000). Transition from School to Work in Comparative Perspective. V: Maureen, T. (ur.), Handbook of the Sociology of Education. New York, Boston: Springer.

Kogan, I., Schubert, F. (2003). Youth Transition from Education to Work Life in Europe: A General Overview. V: Kogan, Irena., Müller, W. (ur.), School to Work Transition in Europe: Analysis of EU LFS 2000 Ad Hoc Module. Mannheim: MZES.

Lenarčič, B. (2008.) Vloga socialnega kapitala pri transferju znanja iz akademskih v gospodarska okolja (The Role of Social Capital in the Transfer of Knowledge from Academic to Economic Environments). V: Podmenik, D. (ur.), Sociokulturni in organizacijski vidiki prenosa znanja (Sociocultural and Organisational Aspects of Knowledge Transfer). Ljubljana: ARRS.

Letno poročilo 2006 (2007). Ljubljana: Zavod Republike Slovenije za zaposlovanje.

Literacy in the Information Age (2000). OECD \& Statistics Canada. Pariz: OECD.

Müller, W., Shavit, Y. (1998). The Institutional Embeddedness of the Stratification Process: A Comparative Study of Qualifications and Occupations in Thirteen Countries. V: Shavit Y., Müller, W. (ur.), From School to Work: A Comparative Study 
of Educational Qualifications und Occupational Destinations. Oxford: Clarendon Press.

Podmenik, D. (2003). Aktivno državljanstvo in socialni kapital. Socialni kapital v Sloveniji. Ljubljana: Sophia.

Podmenik, D., Černigoj Sadar, N., Ivančič, A. (2006). Evalvacija naložb v izobrazbeni kapital in mladinski trg dela. Končno poročilo raziskave CRP. Ljubljana: Inštitut Nove revije, Zavod za humanistiko.

Podmenik, D., Černigoj Sadar, N. (2008). V iskanju izmikajočega se cilja. V: Med javnim in zasebnim, ženske na trgu dela. Koper: Annales.

Podmenik, D. s sodelavci (2010). Inovacijska jedra $v$ regionalnem razvoju. Potenciali znanja - mladi diplomanti na trgu dela. Ljubljana: Založba Vega.

Podmenik, D., Ivančič, A. (neobjavljeno, 2010). More than just a Diploma is Required for Successful Job Matching. (V recenzijskem postopku revije Socialna Politika, Zagreb.)

Ponzo, M., Scoppa, V. (2009). The Use of Informal Networks in Italy: Efficiency or Favoritism? Munich: Personal RePEc Archive, MPRA paper no. 17281.

Putnam, R. D. (1993). Making Democracy Work. New Jersey: Princeton University Press.

Schomburg, H., Teichler, U. (2006). Higher Education and Graduate Employment in Europe. Results from Graduate Surveys from Twelve Countries. Heidelberg: Springer.

Sprangers, M. (1992). Explaining Unemployment Duration. An Integrative Approach. Utrecht: University Utrecht.

Teichler, U. (2003). »The Future of Higher Education and the Future of Higher Education Research «. Tertiary Education and Management, 9: 171-185.

Teichler, U. (2004). Diversification of Higher Education and the Changing Role of Knowledge and Research. Pariz: The UNESCO Forum Regional Scientific Committee.

Vidovič, U. (2003.) Socialni in človeški kapital v študentski populaciji. (Social and Human Capital within the Student Population.) V Makarovič M. (ur.), Socialni kapital v Sloveniji. Ljubljana.

Wolbers, M. (2003). »Job Mismatches and their Labour - Market Effects among School leavers in Europe«. European Sociologica Review, 19, 3: 249-266.

1 Raziskava je bila izvedena v letih 2004-2006 po naročilu ministrstva za šolstvo in šport in ministrstva za znanost, visoko šolstvo in tehnologijo.

2 Mnenja raziskovalcev o obsegu in (ne)ustreznosti t. $i$. neujemajočega zaposlovanja diplomantov (»job mis- match«) so različna. Tako denimo Schomburg in Teichler (2006) zagovarjata stališče, da neujemajoče zaposlitve dolgoročno ne pomenijo »izgube" znanja diplomantov in da se ti na dolgi rok bodisi prilagodijo bodisi najdejo ustreznejšo zaposlitev. Wobers (2003) na drugi strani pa je bolj kritičen do teh oblik zaposlovanja in jih obravnava kot zaposlovanje »v sili« in kot neustrezno za diplomante ter njihovo kariero.

3 V raziskavi vzorca malih visokotehnoloških podjetij v Sloveniji (Adem in drugi, 2010) smo z intervjuji s predstavniki dobili nekaj zanimivih podatkov o kadrovanju: večina za pridobivanje potencialnih strokovnjakov uporablja promocijske dejavnosti od osnovne šole naprej; s fakultet pridobivajo kadre s sodelovanjem pri projektih; večina proučevanih podjetij uporablja zaposlovalno politiko, s katero bodoče mlade sodelavce vzaaja in priučuje. Po njihovem mnenju mladi diplomanti prinašajo v podjetja mladosten zagon, ne pa novega znanja. (Podmenik in drugi, 2010: 100-101.)

4 Beker v svoji študiji starejšega datuma (1962) ugotavlja, da je socialni kapital lahko "protiutež巛 ekonomskim in socialnim primanjkljajem, vključno z nezadostno izobraženostjo staršev.

5 Med klasiki v teoriji socialnega kapitala tudi Putnam (1993) trdi, da socialni kapital generira človeškega prek socialnih povezav na lokalni družbeni ravni. Coleman (1988) trdi, da je socialni kapital komplementaren človeškemu, in ugotavlja, da lahko celo konventira v človeški kapital.

6 Študija, ki temelji na podatkih, zbranih $v$ gospodinjstvih držav EU (European Community Household Panel for the period 1994-1999), kaže razlike med državami EU; neformalne osebne vezi se za pridobivanje zaposlitve pogosteje uporabljajo v Španiji, na Portugalskem, v Grčiji, Italiji, Franciji in Nemčiji, redkeje pa v UK in skandinavskih državah (Pellizzari, 2004; in Ponzo, Scopa, 2009: 5).

7 Raziskava $z$ naslovom Evalvacija naložb v visokošolsko izobraževanje in mladinski trg dela se primarno ukvarja $z$ naložbami v izobrazbeni kapital in ocenami slovenskega mladinskega trga dela, z izkušnjami respondentov z izobraževalci, delodajalci, posredniškimi agencijami in z odnosi med njimi.

8 Vzorec sestavljata dva segmenta populacije: študenti četrtih letnikov težko zaposljivih študijskih usmeritev s Filozofske fakultete, Fakultete za družbene vede in Fakultete za socialno delo v Ljubljani ter Fakultete za humanistične študije v Kopru ter diplomanti družboslovja in humanistike, ki že dalj časa iščejo zaposlitev na trou dela. Vzorca sta bila določena namensko, za zbiranje podatkov pa sta bili uporabljeni dve metodi: anketni vprašalnik za 150 študentov višjih letnikov in polstrukturirani intervjuji za 12 mladih diplomantov iskalcev zaposlitve na trou dela.

9 Raziskavo je izvedla študentska organizacija na vzorcu pet odstotkov slovenske študentske populacije. 